\title{
Penggunaan Transformator Arus Untuk Pencegahan Pemakaian Arus Ilegal
}

\section{Use of Current Transformers for Prevention of Illegal Current Use}

\author{
M. Putra'), Zulkifli Bahri, 2), Muhammad Fadlan Siregar ${ }^{3)}$ \\ 1,2)Program Studi Teknik Elektro, Fakultas Teknik , \\ Universitas Medan Area, Indonesia \\ 3) Prodi Studi Teknik Elektro, Fakultas Teknik, \\ Universitas Tjut Nyak Dhien, Indonesia
}

*Coresponding author: putrahrp18@yahoo.com

\begin{abstract}
Abstrak
Pemadaman listrik adalah suatu hal yang merugikan terlebih jika pemadaman dilakukan pada waktu sibuk seperti jam kerja. Faktor teknis, dimana masalahnya terletak pada power quality. Faktor non teknis, seperti pencurian listrik. Oleh karena itu dibutuhkan pengujian alat transformator arus untuk mencegah pemakaian arus ilegal cara yang baik untuk mencegah pencurian listrik, untuk mencegah/membrantas pencurian listrik maka secara umum digunakan metode Deteksi fisik (physical detection) dan Metode pemakaian pada konsumen (costumer consumption method). Dari hasi pengujian penggunaan transformator arus untuk pencegahan pemakaian arus ilegal Pengujian ini dilakukan dengan mengukur besar arus sisi primer dan sisi sekunder. Linieritas diperoleh bila arus sisi primer sama dengan arus sisi sekunder. Transformator arus yang diuji berasal dari transformator 2 belitan dengan data 220 volt/24 volt (primer/sekunder), dan arus maksimum 5 Ampere pada sisi skunder. Untuk menjadikan transformator tersebut menjadi auto-transformator arus, sisi primer (220 Volt) tidak digunakan, yang digunakan hanya sisi sekundernya (24 Volt).
\end{abstract}

Kata Kunci : power quality, transformator arus, konsumen

\begin{abstract}
Power outages are a thing detrimental especially when outages do such a busy time working hours. Technical factors, where the problem lies in the power quality. Non-technical factors, such as theft of electricity. Therefore the current transformer testing tools needed to prevent the flow of illegal use of a good way to prevent theft of electricity, to prevent / membrantas theft of electricity, the commonly used detection methods (physical detection) and method of use to the consumer (customer consumption method). The resulttest of the use of a current transformer for the prevention of illegal use of the flow test is conducted by measuring the amount of current primary side and secondary side. Linearity is obtained when a current equal to the current primary side secondary side. Current transformers tested were from 2 transformer winding to the data 220 volt / 24 volt (primary / secondary), and a maximum current of 5 Ampere on the secondary side. To make it into the auto-transformer current transformer, primary side (220 Volt) is not used, used only the secondary side (24 Volt).
\end{abstract}

Keywords : power quality, Current transformers, costumer 
How to Cite : Zulkifli Bahri, Muhammad Fadlan Siregar, M. Putra, Penggunaan Transformator Arus Untuk Pencegahan Pemakaian Arus Ilegal, 2(1) : 21-25

\section{PENDAHULUAN}

Pemadaman listrik adalah suatu hal yang merugikan terlebih jika pemadaman dilakukan pada waktu sibuk seperti jam kerja. Tanpa adanya listrik praktis tidak banyak hal yang dapat dilakukan. Indonesia termasuk negara yang suplai energi listrinya sangat kecil, dibandingkan dengan luas daerah dan jumlah penduduk.

Untuk itu pemadaman bergilir adalah konsekuensi yang harus diterima ketika konsumsi energi ysng tinggi tidak diimbangi dengan ketersediaan sumber energi. Hal ini dipengaruhi dengan kondisi kelistrikan yang tak terkontrol sehingga terjadi losses yang sangat besar. Ada dua pengaruh yang mempengaruhi losses tersebut.

Faktor teknis, dimana masalahnya terletak pada power quality. Faktor non teknis, seperti pencurian listrik. Faktor teknis dapat diatasi lebih mudah dibandingkan dengan factor non teknis, karena tidak dapat diprediksi. Oleh karena itu dibutuhkan cara yang baik untuk mencagah pencurian listrik.

Metode yang umum digunakan untuk mencegah/membrantas pencurian listrik, yaitu:

Deteksi fisik (physical detection), adalah metode yang dilakukan dengan mencari jejak pencurian dalam perangkat pada meteran listrik seperti, pemeriksaan segel, kabel listrik tambahan

yang pemasangannya tidak sesuai dengan standarisasi. Metode pemakaian pada konsumen (costumer consumption method).

\section{METODE PENELITIAN}

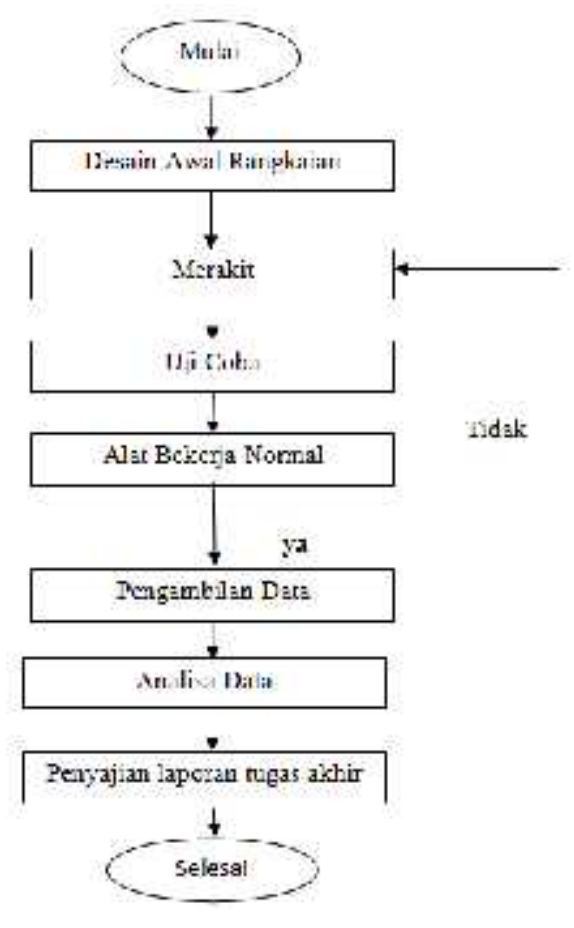

Gambar1. Flow Chart Penelitian

Peralatan pencegahan pemakaian arus ilegal yang dirancang menggunakan transformator arus. Alasan pemakaian transformator arus dengan satu belitan (autotransformator) tegangan adalah:

a. Mempunyai ratio (faktor transformasi) $=1$, akibatnya arus primer sama dengan arus sekunder transformator. Dengan demikian pembacaan nilai watt atau watthour tidak perlu lagi dikalibrasi dengan faktor transformasi dari transformator yang digunakan.

b. Karena hanya menggunakan satu belitan, maka bentuk fisiknya lebih kecil Transformator arus (CT) yang banyak dijual di pasaran adalah transformator arus dengan faktor transformasi yang cukup besar, misalnya 100/5 Ampere, sehingga hal ini menyulitkan dalam 
perencanaan alat pencegah pemakaian arus ilegal. Oleh karena itu dalam peralatan simulasi pencegahan pemakaian arus ilegal ini hanya menggunakan daya beban yang kecil tanpa mempengaruhi sistem kerja alat.

Transformator dengan factor transformasi yang besar dapat digunakan sebagai alat pencegahan pemakaian arus ilegal pada industri dengan kapasitas daya yang besar. Transformator yang digunakan dalam simulasi alat pencegahan pemakaian arus ilegal ini adalah transformator step-down dengan dua belitan terpisah, yang banyak dijual di pasaran dengan data:

Tegangan sisi primer : 110/220 Volt

Tegangan sisi sekunder : 24 Volt

Arus pada sisi sekuder : 5 Ampere

Sisi sekunder transformator dengan tegangan 24 volt dan arus 5 Ampere dijadikan sebagai autotransformator arus dengan alasan :

1. Kemampuan arusnya lebih besar dibandingkan arus sisi primer sehingga dapat melayani beban yang besar.

2. Karena tegangan pada sisi primer lebih tinggi dari belitan sekunder, jumlah belitan sisi primer lebih banyak dibandingkan jumlah belitan-belitan sekunder. Diameter konduktor yang digunakan pada sisi primer lebih kecil dari diameter konduktor sisi sekunder. Akibatnya resitansi pada sisi primer lebih besar dari resitansi pada sisi sekunder. Resistansi yang besar menimbulkan rugirugi tegangan yang lebih besar dibandingkan rugi-rugi tegangan pada resistansi yang kecil.

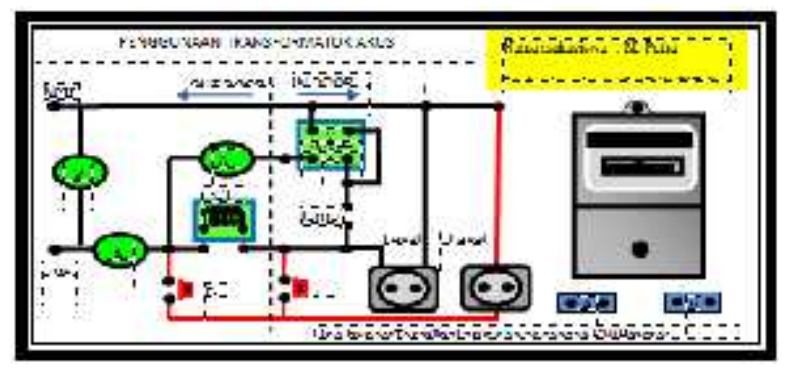

Gambar 2. Pengunaan transformator arus untuk mencegah pengunaan arus listrik ilegal

\section{HASIL DAN PEMBAHASAN}

Pengujian ini dilakukan dengan mengukur besar arus sisi primer dan sisi sekunder. Linieritas diperoleh bila arus sisi primer sama dengan arus sisi sekunder. Transformator arus yang diuji berasal dari transformator 2 belitan dengan data 220 volt/24 volt primer/sekunder), dan arus maksimum 5 Ampere pada sisi skunder.

Untuk menjadikan transformator tersebut menjadi auto-transformator arus, sisi primer (220 Volt) tidak digunakan, yang digunakan hanya sisi sekundernya (24 Volt).

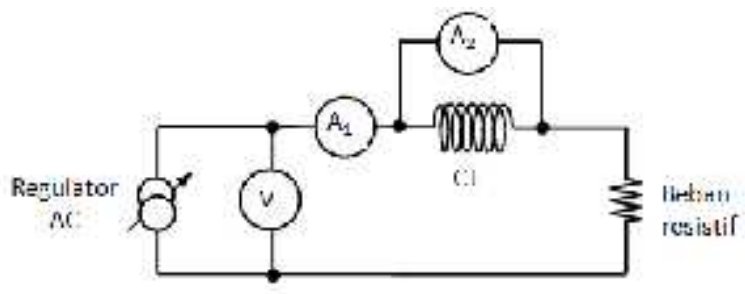

Gambar 3. Rangkaian pengujian linieritas autotransformator arus.

Alat-alat ukur yang digunakan dalam pengujian:

1. Autotransformator/regulator $0-240 \mathrm{~V} / 500 \mathrm{VA}$, Matsunaga Japan, 1 buah

2. Volt-ampere meter, Tipe 2014/Yokogawa, Japan, 2 buah

3. Watt Meter 1 fasa $5 ; 25 \mathrm{Amp} / 120 ; 240 \mathrm{~V}$, Tipe 2041/Yokogawa 1 buah

4. Multimeter digital tipe CD 702 Sanwa, Japan,1 buah 
M. Putra, Zulkifli Bahri, Muhammad Fadlan Siregar, Penggunaan Transformator Arus Untuk Pencegahan

5. KWH Meter 1 fasa/220 volt, Tipe FA 141A, Fuji Electric , 1 buah

6. Amperemeter 5 A, tipe CR 52, class 2,5 ,TAB, 2 buah

7. Voltemeter 300 Volt, CR 52 class : 2,5, Heles 1 buah

8. Transformator arus 5 Ampere (transformator yang diuji) ,1 buah

9. Beban lampu pijar $4 \times 100$ watt/220 Volt, 1 set 10. Beban lampu pijar $2 \times 100$ watt/220 Volt. 1 set

Pengujian transformator arus dilakukan dengan beban resistif yang konstan (lampu pijar $4 \times 100$ watt). Dengan menaikkan arus primer $\left(A_{1}\right)$ secara bertahap melalui regulator $\mathrm{AC}$, dicatat $\mathrm{p}$ tegangan primer (V) transformator arus dan arus sekunder $\left(A_{2}\right)$.

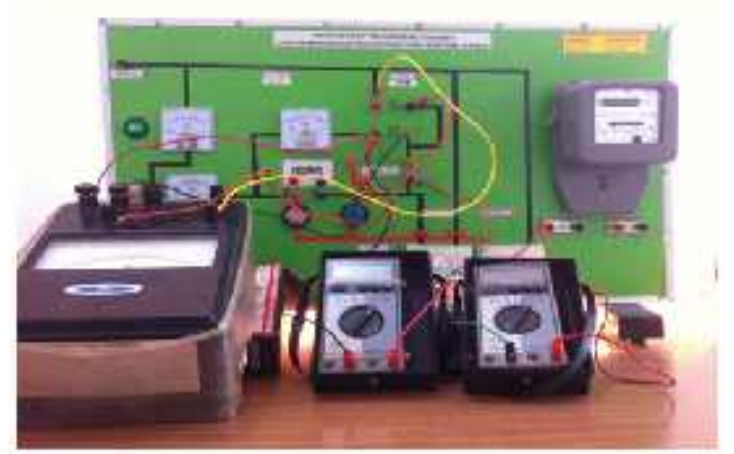

Gambar4. Rangkaian Percobaan

Tabel 1. Hasil Pengujian Linieritas Transformator Arus

\begin{tabular}{|c|c|c|c|c|c|c|c|c|}
\hline No, & 1 & 2 & 3 & 1 & 5 & 5 & $\tau$ & 8 \\
\hline $\begin{array}{l}\text { eggrogn primor } \\
\text { (xilil) }\end{array}$ & 15 & 10 & 45 & (1) & 73 & 9n? & las & 124 \\
\hline Nuss primes $(a n+g)$ & $0 . \div$ & n.1s & 19.22 & $3 \pi 6$ & 19.29 & $41.5 !$ & 1). .16 & B_s\% \\
\hline $\begin{array}{l}\text { A:v: } \\
\text { (Amp) }\end{array}$ & 0.2 & 0.13 & 022 & 2.23 & 0.30 & 031 & 0.37 & 0.11 \\
\hline
\end{tabular}

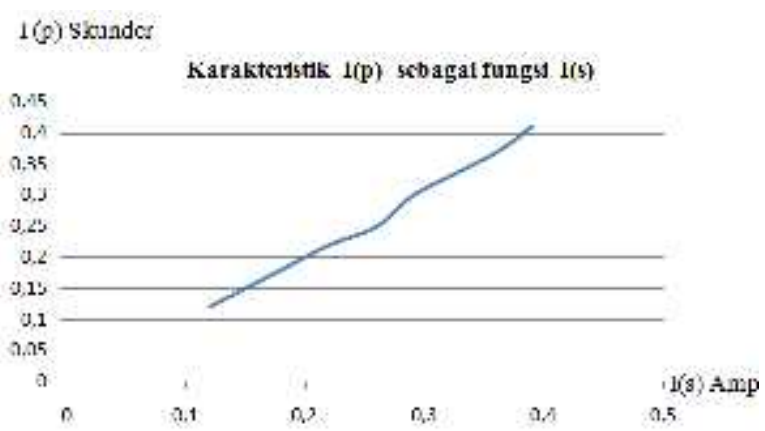

Gambar 5. Karakteristik IP sebagai fungsi IS.

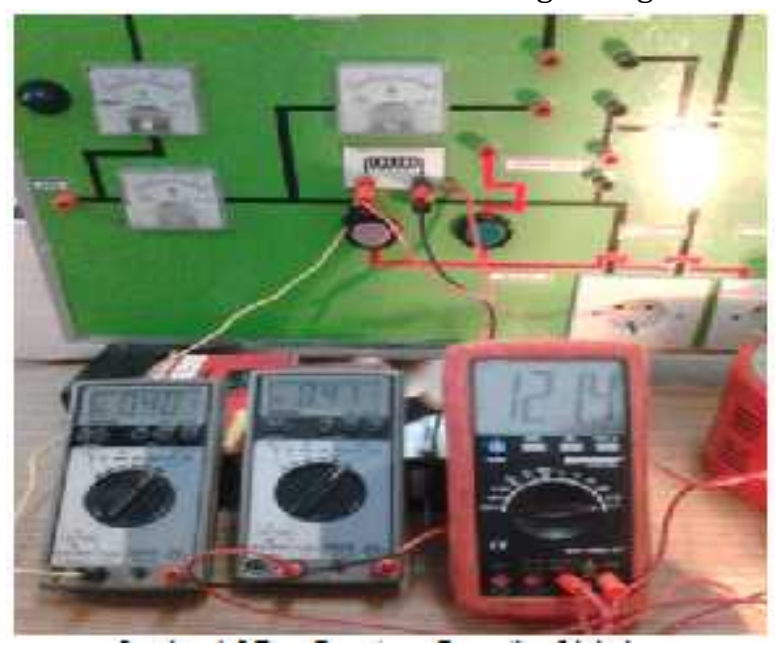

Gambar 6. Rangkaian Percobaan Pengujian Linieritas

Pengujian peralatan pencegahan penggunaan arus illegal

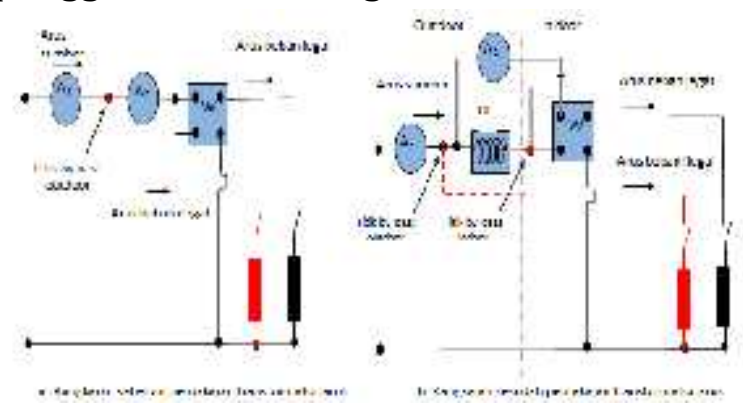

Gambar7. Rangkaian pengujian 


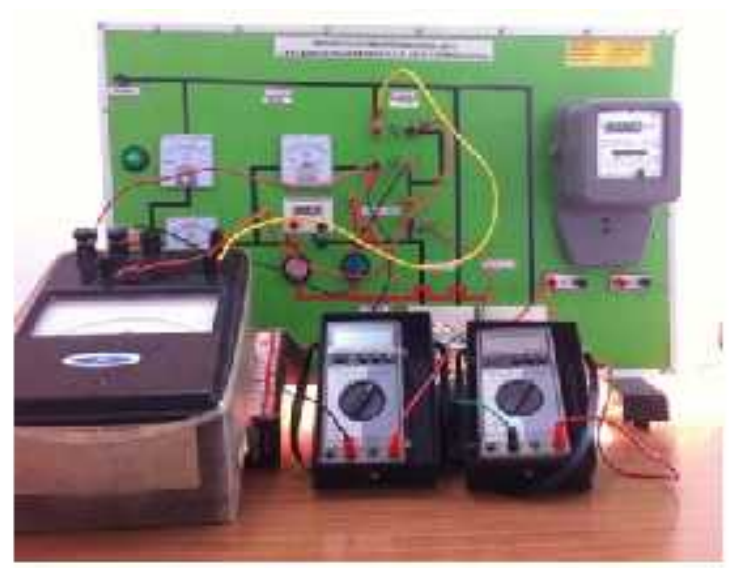

Gambar8. Rangkaian Percobaan Pengujian

Tabel 2. Hasil Pengujian Arus Legal dan Ilegal yang Terdeteksi

\begin{tabular}{|c|c|c|c|c|c|c|}
\hline \multicolumn{3}{|c|}{ Xinulisi } & $\begin{array}{l}\text { Aros } \\
\text { sambicy } \\
\text { (xmp) }\end{array}$ & $\begin{array}{l}\text { Arus kution } \\
\text { sezal (ans) }\end{array}$ & 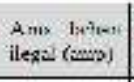 & $\begin{array}{l}\text { DגFe } \\
\text { hilisn } \\
(w \rightarrow 1)\end{array}$ \\
\hline \multicolumn{3}{|c|}{ Siloxn le(ux) } & $1 \times x$ & $1 \mathrm{xg}$ & 1. & $x y 3$ \\
\hline \multirow[t]{2}{*}{2} & \multicolumn{2}{|c|}{ 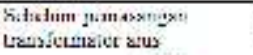 } & 2,99 & $1, \$ 5$ & 1.11 & 350 \\
\hline & Sis: 2 th & $\begin{array}{l}\text { Arus } \\
\text { Sismint } \\
\text { seldsti }(+1\end{array}$ & 200 & 188 & 1.11 & tan \\
\hline ; & CT & $\begin{array}{l}\text { Arus } \\
\text { fiambi } \\
x^{*} \text { to } x^{*} \text { inm (7) }\end{array}$ & 259 & I Ki & 111 & $4 a$ \\
\hline
\end{tabular}

\section{SIMPULAN}

Dengan menggunakan alat ini, akan lebih mudah untuk mengetahui pencuriaan arus listrik.

Transformator CT bisa di gunakan alasan sebagai autotansformator, mempunyai ratio(faktor transformasi), dan karena hanya mengunakan satu belitan sisi skunder

\section{DAFTAR PUSTAKA}

Chapman, Stephen J.( 1991) Electrical Machinery Fundamental. McGraw Hill International Edition, New York.

Fitzgerald, AE and Charles Kingsley. (1991) Machinery Fundamentaal. McGraw Hill Inter-national Edition, New York.

Hughes, E. Electrical Technology. The English Language Book Society and Longman Group Ltd.

Lister, Eugene C. (1984) Electric Circuits and Machines. McGraw Hill International Edition, New York.
Kuznetsov, M. Fundamental of Electrical Engineering.Peace Publisher, Moscow

Nagrath, IJ and DP Kothari, (1989) Electrical Machines. Tata McGraw Hill Publishing Company Limited, New Delhi.

Sapii, Soedjana. Pengukuran Dan Alat Ukur Listrik. Penerbit Pradnya Paramita Jakarta

Tarnekar, SG and PK Kharbanda. Laboratory Courses in Electrical Engineering. S. Chand \& Company,New Delhi

Theraja, B.L, A (1988) Text Book of Electrical Technology, S. Chand \& Company Ltd, Ram Nagar, New Delhi,

Whitemore, Arthur. Electrical Measurement. McGraw Hill International Student Edition 